\title{
Extracorporeal membrane oxygenation after lung transplantation: risk factors and outcomes analysis
}

\author{
Massimo Boffini ${ }^{1}$, Erika Simonato ${ }^{1}$, Davide Ricci ${ }^{1}$, Fabrizio Scalini ${ }^{1}$, Matteo Marro ${ }^{1}$, Stefano Pidello ${ }^{1}$, \\ Matteo Attisani ${ }^{1}$, Paolo Solidoro ${ }^{2}$, Paolo Olivo Lausi ${ }^{3}$, Vito Fanelli ${ }^{4}$, Cristina Barbero ${ }^{1}$, Luca Brazzi ${ }^{4}$, \\ Mauro Rinaldi ${ }^{1}$ \\ ${ }^{1}$ Cardiac Surgery Division, Surgical Sciences Department, ${ }^{2}$ Pulmonology Division, Medical Sciences Department, ${ }^{3}$ Thoracic Surgery Division, \\ Surgical Sciences Department, ${ }^{4}$ Anesthesiology and Intensive Care Division, Surgical Sciences Department, Città della Salute e della Scienza, \\ University of Torino, Turin, Italy \\ Correspondence to: Prof. Massimo Boffini, MD. Cardiac Surgery Division, Surgical Sciences Department, Città della Salute e della Scienza, University \\ of Torino, Corso Bramante 88/90, 10182 Turin, Italy. Email: massimo.boffini@unito.it.
}

\begin{abstract}
Background: Lung transplantation is the treatment of choice for end-stage pulmonary disease in selected patients. However, severe primary graft dysfunction is a significant complication of transplant and requires the implantation of an extracorporeal support. The aim of the study is to evaluate the impact of extracorporeal membrane oxygenation (ECMO) after transplant in our center.

Methods: From January 2008 till June 2018, 195 consecutive unselected patients receiving a lung transplant were considered. Mean age was $49 \pm 15$ years. Main indications for transplant were idiopathic pulmonary fibrosis in 72 patients, chronic obstructive pulmonary disease in 60 patients, and cystic fibrosis in 40 patients. Prior to transplant, 18 patients were on mechanical ventilation and 14 were on ECMO.

Results: Twenty-five patients required venous-venous ECMO after transplant. Vascular disease as cause of transplant [relative risk (RR) 7.8, 95\% CI: 1.5-41, P=0.02], donor age (RR 1.6, 95\% CI: 1.03-2.3, P=0.03) and need for cardiopulmonary by-pass during transplant (RR 3.1, 95\% CI: 1.02-9, P=0.04) were associated with ECMO implantation. Patients requiring post-transplant ECMO received more transfusions $(\mathrm{P}<0.01)$, had a longer mechanical ventilation $(\mathrm{P}<0.01)$ and ICU stay $(\mathrm{P}<0.01)$ and had a higher hospital mortality $(\mathrm{P}<0.01)$. Post-transplant ECMO significantly influenced one- and five-year survival [hazard ratio (HR) 5.5, 95\% CI: 3-10, $\mathrm{P}<0.001$ and HR 3.5, 95\% CI: 2-6, $\mathrm{P}<0.001$, respectively]. However, conditional survival after $\mathrm{t}$ months is similar for patients with or without post-transplant ECMO.

Conclusions: In our experience, although ECMO is a reliable and effective strategy to support pulmonary function, severe graft dysfunction after lung transplantation still has a significant impact on early and late results.
\end{abstract}

Keywords: Extracorporeal membrane oxygenation (ECMO); lung transplantation (LTx); primary graft dysfunction

Submitted Sep 20, 2018. Accepted for publication Dec 21, 2018.

doi: $10.21037 /$ acs.2018.12.10

View this article at: http://dx.doi.org/10.21037/acs.2018.12.10

\section{Introduction}

Lung transplantation (LTx) is the ultimate therapy for selected patients with end-stage respiratory insufficiency $(1,2)$. LTx is characterized by a long waiting period due to a low rate of lung graft suitability among the pool of available donors. Moreover, unstable patients can receive only supportive therapies such as mechanical ventilation and or extracorporeal oxygenation for a limited period of time $(3,4)$. However, the clinical armamentarium has evolved in recent years. Procedures of ex-vivo lung perfusion (EVLP) allow a better evaluation and in some 


\begin{tabular}{|c|c|}
\hline Characteristics & Value \\
\hline Age at transplant, mean $\pm \mathrm{SD}$ [range] (years) & $49 \pm 15[11-69]$ (median 54) \\
\hline Male sex, $n[\%]$ & 123 [63] \\
\hline Waiting time on the waiting list, mean \pm SD [range] (days) & $256 \pm 329[1-2,402]($ median 141$)$ \\
\hline Idiopathic pulmonary fibrosis & $72[37]$ \\
\hline COPD & $60[31]$ \\
\hline Cystic fibrosis & $40[21]$ \\
\hline Vascular diseases & $9[5]$ \\
\hline Urgent LTx, n [\%] & 23 [12] \\
\hline Ex vivo lung perfusion, $n$ [\%] & $32[16]$ \\
\hline Bilateral lung transplantation, $\mathrm{n}[\%]$ & $157[81]$ \\
\hline Mean ischemic time, mean $\pm \mathrm{SD}$ [range] (min) & $376 \pm 184[376-1,380]$ \\
\hline Donor age, mean \pm SD [range] (years) & $44 \pm 14[7-69]($ median 47) \\
\hline Length of donor's mechanical ventilation, mean \pm SD [range] (days) & $3 \pm 2[1-9]($ median 2) \\
\hline $\mathrm{P} / \mathrm{F}$ ratio at $100 \%$ of $\mathrm{O}_{2}$ [range] & $465 \pm 91[209-648]$ (median 463) \\
\hline
\end{tabular}

$\mathrm{SD}$, standard deviation; COPD, chronic obstructive pulmonary disease; ECMO, extracorporeal membrane oxygenation; P/F, ratio of arterial oxygen concentration to the fraction of inspired oxygen.

cases a recondition of otherwise unusable grafts (5-7). Although still limited in some centers, donation after cardiac death (DCD) is growing with a potential increase of the donor pool (8). Lastly, evolution of extracorporeal oxygenation technologies allows a more effective and longer supportive therapy both pre- and post-transplant (3). The aim of this study is to evaluate the impact of extracorporeal membrane oxygenation (ECMO) in the post-transplant period in our center in the last ten years.

\section{Methods}

From January 2008 till June 2018, 195 consecutive LTx were performed at Città della Salute e della Scienza, University Hospital in Turin. Mean age at transplant was $49 \pm 15$ (range, 11-69) years. Mean time on the waiting list was $256 \pm 329$ (range, 1-2,402) days with a median of 141 days. Main indications for LTX were: idiopathic pulmonary fibrosis (IPF) in 72 patients (37\%), chronic obstructive pulmonary disease (COPD) in 60 patients (31\%), and cystic fibrosis in $40(21 \%)$ patients. Twenty-three patients (12\%) received a transplant on an urgent basis. According to a national protocol, urgent lung transplant was reserved for young listed patients (Age $\leq 50$ years) requiring mechanical ventilation and/or extracorporeal lung support with ECMO or Novalung (4).

Eighteen (9\%) and 14 (7\%) patients were on mechanical ventilation and ECMO before transplant, respectively. Table 1 summarizes recipients' and donors' characteristics. Lung graft has been preserved with an antegrade and retrograde flush with Perfadex ${ }^{\circledR}$ and cold storage at $4{ }^{\circ} \mathrm{C}$ before transplant. Thirty-two grafts considered unsuitable for direct transplantation underwent EVLP before transplant. Mean ischemic time was $376 \pm 184$ (range, 119-1,380) minutes. Lung transplant has been performed according to the standard technique. Cardiopulmonary 
bypass was used in case of poor oxygenation on monolateral ventilation, hemodynamic instability after pulmonary artery clamping or in patients on extracorporeal ventilation before transplant. One hundred and fifty-seven patients $(81 \%)$ received a bilateral graft. Single lung transplant has been performed in selected cases only on patients with parenchymal disease without history of infection and/or pulmonary hypertension.

\section{Statistical analysis}

Descriptive statistics are presented as mean, median, standard deviation and ranges for the continuous variables, and as counts and percentages for categorical variables. Comparisons between groups were performed using a $\chi^{2}$ test or ANOVA test as appropriate. All significant variables at univariate analysis were included in a Cox regression multivariate analysis with a stepwise forward conditional method. Kaplan-Meier curves were used to evaluate eventfree survival according to categorical variables, compared by the Mantel-Cox test. A two-sided $\mathrm{P}$ value $<0.05$ was considered statistically significant; all analyses were performed with SPSS 20.0 (IBM corp., Armonk, NY, USA).

\section{Results}

Twenty-five patients $(12.8 \%)$ required venous-venous ECMO after transplant for a mean time of $8 \pm 8$ (range, 1-30, median 5) days. ECMO was accomplished through the insertion of a cannula from the left femoral vein up to the right atrium for the input and through a second cannula from the right femoral vein with the tip just below the junction between the inferior vena cava and the right atrium for drainage. After heparin administration (with a target activated clotting time of 200 seconds), cannulas were inserted under the guidance of a transesophageal echocardiogram to check the correct position. The cannulas were then connected to an ECMO circuit and extracorporeal support initiated. During support, a protective lung ventilation protocol was applied. Cardiac function was also checked to identify the onset of right or left ventricular failure. Univariate analysis showed that patients requiring ECMO after transplant suffered more frequently from vascular disease (pulmonary hypertension or Eisenmenger syndrome) as cause of transplant, had higher pulmonary artery pressure, were more frequently on mechanical ventilation or on ECMO before transplant, required cardiopulmonary bypass during transplant more frequently and received a graft from an older donor (Table 2). Independent risk factors for post-transplant ECMO were: vascular disease as cause of transplant [relative risk (RR) 7.8, 95\% CI: 1.5-41, $\mathrm{P}=0.02$ ], donor age (RR 1.6, 95\% CI: $1.03-2.3, \mathrm{P}=0.03)$ and need of cardiopulmonary bypass during LTx (RR 3.1, 95\% CI: 1.02-9, P=0.04) (Table 3). Patients requiring post-transplant ECMO received transfusions more frequently $(\mathrm{P}<0.01)$, had a greater duration of mechanical ventilation $(\mathrm{P}<0.01)$ and ICU stay $(\mathrm{P}<0.01)$, and had a higher hospital mortality $(\mathrm{P}<0.01)$ (Table 4).

Among the 24 patients supported with ECMO after LTX, in 18 (75\%) patients ECMO has been weaned after $8.8 \pm 8.9$ (range, 1-30, median 5) days. Duration of ECMO support did not differ between weaned and not weaned patients $(\mathrm{P}=0.64)$. Hospital mortality was higher in patients with unsuccessful weaning $(\mathrm{P}<0.001)$ (Table 5). Overall hospital mortality was $12.3 \%$. At univariate analysis, hospital mortality was influenced by the following factors: need for cardiopulmonary bypass during LTx $(\mathrm{P}=0.03)$, pre-transplant mechanical ventilation $(\mathrm{P}<0.01)$, pretransplant ECMO $(\mathrm{P}<0.01)$, urgent $\mathrm{LTx}(\mathrm{P}<0.01)$ (Table 6). ECMO after LTx (RR 7.7, 95\% CI: 2.8-21, P<0.01) and pre-transplant mechanical ventilation (RR 4.6, 95\% CI: 1.4-15, $\mathrm{P}<0.01)$ were identified as independent risk factors for hospital mortality (Table 7). One- and five-year survival rates were $73 \%$ and $48 \%$, respectively. Post-transplant ECMO significantly influenced one- and five-year survival [hazard ratio (HR) 5.5, 95\% CI: 3-10, P<0.001 and HR 3.5, 95\% CI: 2-6, $\mathrm{P}<0.001$, respectively] (Figure 1). However conditional survival after 3 months is similar for patients with or without post-transplant ECMO (Figure 2).

\section{Discussion}

The present study shows our experience on consecutive unselected patients receiving LTx in our center during the last ten years. The analysis has been focused on primary graft dysfunction with the need for ECMO after transplant. Improvements in ECMO technology have led to a safer and more effective support of lung function either before and after surgery, however, post-transplant severe graft dysfunction (although supported by ECMO) still remains a significant risk factor for poor survival after LTx (9).

The main findings of the present analysis are that vascular disease as an underlying cause of transplant is independently associated with post-transplant ECMO, and 
Table 2 Univariate analysis for need of ECMO after lung transplantation

\begin{tabular}{|c|c|c|c|}
\hline Variables & ECMO after LTx $(n=25)$ & No ECMO after LTx $(n=170)$ & $P$ value \\
\hline Mean waiting time on LTx list, mean \pm SD (days) & $327 \pm 475$ & $245 \pm 304$ & 0.24 \\
\hline Cause of lung disease, $n$ [\%] & & & $<0.01$ \\
\hline Cystic fibrosis & $5[20]$ & $35[21]$ & \\
\hline Idiopathic pulmonary fibrosis & $9[36]$ & $63[37]$ & \\
\hline Vascular disease & $5[20]$ & $4[2]$ & \\
\hline sPAP, mean \pm SD $(\mathrm{mmHg})$ & $51 \pm 20$ & $39 \pm 13$ & $<0.01$ \\
\hline $\mathrm{mPAP}$, mean $\pm \mathrm{SD}(\mathrm{mmHg})$ & $36 \pm 16$ & $25 \pm 9$ & $<0.01$ \\
\hline Need for CPB during transplant, $\mathrm{n}[\%]$ & $17[68]$ & $43[25]$ & $<0.01$ \\
\hline Mechanical ventilation before transplant, $\mathrm{n}$ [\%] & $6[24]$ & $12[7]$ & $<0.01$ \\
\hline ECMO before transplant, $\mathrm{n}[\%]$ & $6[24]$ & $8[5]$ & $<0.01$ \\
\hline Urgent LTx, n [\%] & 7 [28] & $16[9]$ & $<0.01$ \\
\hline Donor age, mean \pm SD (years) & $49 \pm 10$ & $43 \pm 14$ & $<0.01$ \\
\hline
\end{tabular}

ECMO, extracorporeal membrane oxygenation; LTx, lung transplant; SD, standard deviation; COPD, chronic obstructive pulmonary disease; sPAP, systolic pulmonary artery pressure; mPAP, mean pulmonary artery pressure; CPB, cardiopulmonary by-pass; P/F, ratio of arterial oxygen concentration to the fraction of inspired oxygen.

Table 3 Multivariate analysis for need of ECMO after lung transplantation

\begin{tabular}{llll}
\hline Variables & RR & $95 \%$ Cl & P value \\
\hline Vascular disease as cause of transplant & 7.8 & $1.5-41$ & 0.02 \\
\hline Donor age (per 10 years increase) & 1.6 & $1.03-2.3$ & 0.03 \\
\hline Need for CPB during LTx & 3.1 & $1.02-9$ & 0.04 \\
\hline ECMO before LTx & 3.3 & $0.8-14$ & 0.10 \\
Mechanical ventilation before LTx & 2.0 & $0.2-29$ & 0.60 \\
\hline Urgent LTx (n, \%) & 0.7 & $0.1-15$ & 0.80 \\
\hline $\begin{array}{l}\text { RR, relative risk; Cl, confidence interval; CPB, cardiopulmonary by-pass; LTx, lung transplant; ECMO, extracorporeal membrane } \\
\text { oxygenation. }\end{array}$ & &
\end{tabular}


Table 4 Comparison of lung transplanted patients with or without need of post-transplant ECMO

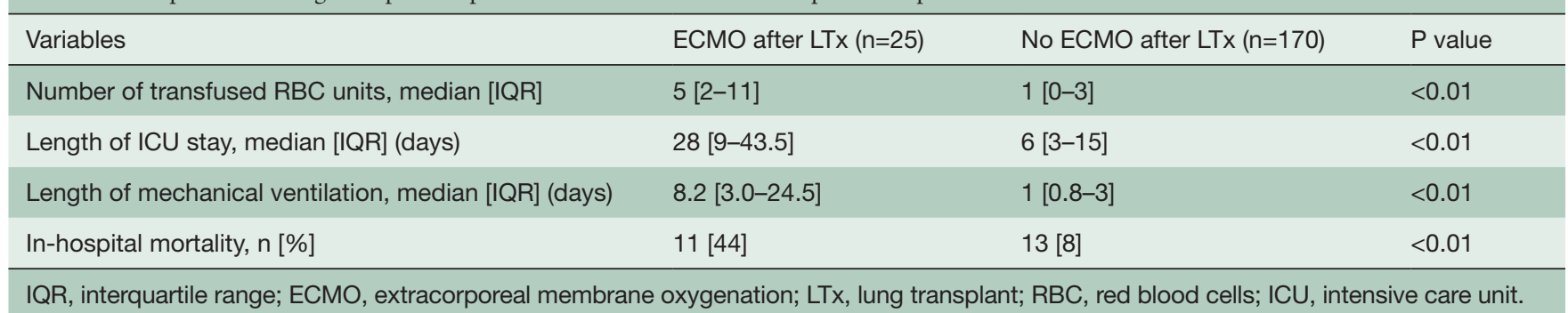

\begin{tabular}{|c|c|c|c|}
\hline Variables & Successful weaning $(n=18)$ & No weaning $(n=6)$ & $P$ value \\
\hline Age at transplant, mean $\pm \mathrm{SD}$ (years) & $46 \pm 17$ & $42 \pm 15$ & 0.64 \\
\hline Waiting time on LTx list, mean \pm SD (days) & $233 \pm 218$ & $586 \pm 900$ & 0.12 \\
\hline Vascular disease as cause of LTx, $n$ [\%] & 4 [22] & $1[17]$ & 0.77 \\
\hline Need for CPB during LTx, n [\%] & 12 [67] & 5 [83] & 0.46 \\
\hline Mechanical ventilation at LTx, $\mathrm{n}$ [\%] & $3[17]$ & $3[50]$ & 0.11 \\
\hline ECMO at LTx, n [\%] & $3[17]$ & $3[50]$ & 0.11 \\
\hline Urgent LTx, n [\%] & $4[22]$ & $3[50]$ & 0.25 \\
\hline Hospital mortality, n [\%] & $4[22]$ & $6[100]$ & 0.001 \\
\hline $\mathrm{P} / \mathrm{F}$ ratio at $100 \%$ of $\mathrm{O}_{2}>350, \mathrm{n}[\%]$ & 12 [67] & $5[83]$ & 0.46 \\
\hline Ischemic time, mean \pm SD (min) & $359 \pm 218$ & $169 \pm 57$ & 0.58 \\
\hline Donor age, mean $\pm \mathrm{SD}$ (years) & $50 \pm 10$ & $50 \pm 10$ & 0.96 \\
\hline
\end{tabular}

$\mathrm{SD}$, standard deviation; LTx, lung transplant; CPB, cardiopulmonary by-pass; ECMO, extracorporeal membrane oxygenation; P/F, ratio of arterial oxygen concentration to the fraction of inspired oxygen.

that ECMO support has a significant impact on early and late outcomes. Pulmonary hypertension is a well-known risk factor for severe primary graft dysfunction. This is due to the particular pathophysiology of pulmonary hypertension. High pressures in the pulmonary artery cause hypertrophy and enlargement of right ventricle with a normal or even small left ventricle. A D-shape pattern with a leftward shift of the inter-ventricular septum is always present. The left ventricle usually maintains a preserved systolic function but suffers from different degrees of diastolic dysfunction. After transplant, there is a significant decrease of right ventricular afterload and an important increase of left ventricular preload. Therefore, evaluation of left ventricular diastolic function is crucial in the pre-transplant phase in order to identify the correct surgical strategy (bilateral lung or heart and LTx). Intraoperative and postoperative management of
LTx in the pulmonary hypertension setting is challenging. During surgery, hemodynamic instability is usually related to a worsening right ventricular function due to the increased afterload after pulmonary artery clamping. Extracorporeal circulatory support is therefore always needed to maintain hemodynamic stability. Moreover, extracorporeal support during transplant allows a controlled and smoother reperfusion phase that reaches its maximal critical point intra-operatively during the implantation of the second graft (10). After transplant, the left ventricle receives a huge amount of blood due to the dramatic decrease in right ventricular afterload. For these reasons, some centers suggest maintaining a venous-arterial ECMO in the postoperative period to allow a progressive adaptation of the left ventricle to the new hemodynamic condition (11-13). Recently, Moser et al. from Vienna reported their 
Table 6 Univariate analysis of hospital mortality

\begin{tabular}{|c|c|c|c|}
\hline Variables & Dead $(n=24)$ & Alive $(n=171)$ & $P$ value \\
\hline Male sex, $\mathrm{n}[\%]$ & $13[54]$ & $110[64]$ & 0.37 \\
\hline Time on waiting list, mean \pm SD (days) & $313 \pm 507$ & $248 \pm 298$ & 0.36 \\
\hline Indication for LTx, n [\%] & & & 0.14 \\
\hline Cystic fibrosis & $2[8]$ & 38 [22] & \\
\hline Idiopathic pulmonary fibrosis & $13[54]$ & 59 [34] & \\
\hline Vascular disease & $1[4]$ & $8[5]$ & \\
\hline $\mathrm{mPAP}$, mean $\pm \mathrm{SD}(\mathrm{mmHg})$ & $30 \pm 12$ & $26 \pm 10$ & 0.09 \\
\hline Need for CPB during LTx, $n$ [\%] & $12[50]$ & 48 [28] & 0.03 \\
\hline Mechanical ventilation before LTx, $\mathrm{n}$ [\%] & 7 [29] & $11[6]$ & $<0.01$ \\
\hline ECMO before LTx, n [\%] & $5[21]$ & $9[5]$ & $<0.01$ \\
\hline Urgent LTx, n [\%] & 8 [33] & $15[9]$ & $<0.01$ \\
\hline Ischemic time, mean $\pm \mathrm{SD}$ (min) & $338 \pm 86$ & $379 \pm 190$ & 0.44 \\
\hline Donor age, mean $\pm \mathrm{SD}$ (years) & $48 \pm 16$ & $43 \pm 14$ & 0.13 \\
\hline
\end{tabular}

$\mathrm{SD}$, standard deviation; COPD, chronic obstructive pulmonary disease; sPAP, systolic pulmonary artery pressure; mPAP, mean pulmonary artery pressure; CPB, cardio-pulmonary by-pass; LTx, lung transplant; ECMO, extracorporeal membrane oxygenation.

\begin{tabular}{|c|c|c|c|}
\hline Variables & $\mathrm{RR}$ & $95 \% \mathrm{Cl}$ & $P$ value \\
\hline ECMO after LTX & 7.7 & $2.8-21$ & $<0.01$ \\
\hline $\begin{array}{l}\text { Mechanical ventilation } \\
\text { before LTx }\end{array}$ & 4.6 & $1.4-15$ & $<0.01$ \\
\hline $\begin{array}{l}\text { Donor age } \\
\text { (per } 10 \text { years increase) }\end{array}$ & 1.1 & $0.9-1.2$ & 0.44 \\
\hline ECMO before LTX & 0.8 & $0.2-4.5$ & 0.82 \\
\hline Need for CPB during LTx & 0.8 & $0.3-2.9$ & 0.80 \\
\hline Urgent LTx (n, \%) & 2.6 & $0.2-33$ & 0.57 \\
\hline
\end{tabular}

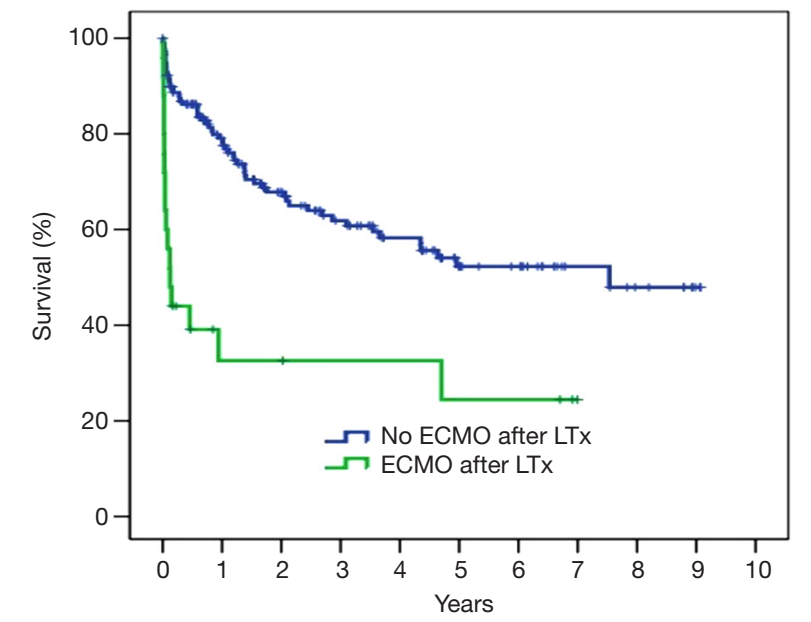

Figure 1 Kaplan-Meier survival curves stratified according to the need of post-transplant ECMO. ECMO, extracorporeal membrane oxygenation. 


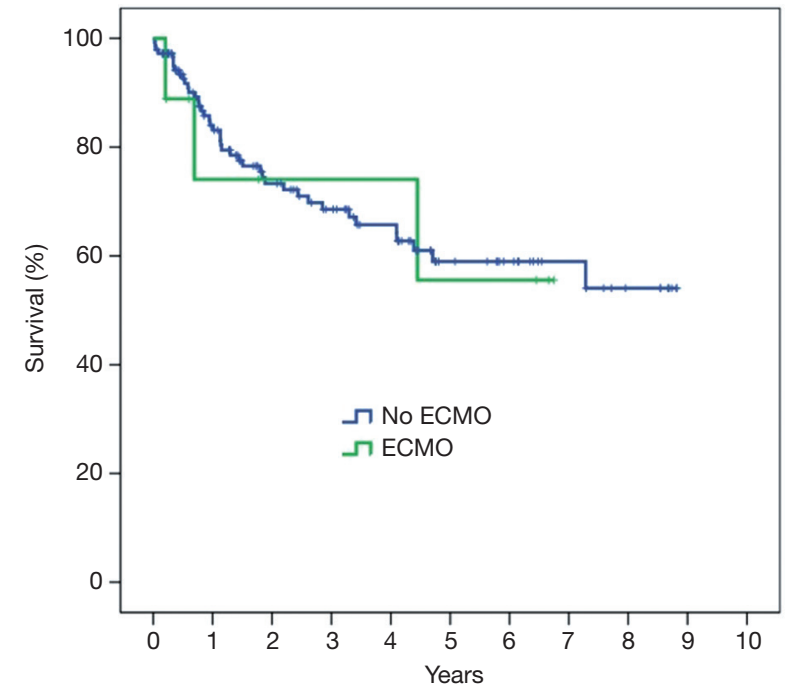

Figure 2 Kaplan-Meier survival curves conditional on survival to 3 months. ECMO, extracorporeal membrane oxygenation.

experience on LTx for idiopathic pulmonary hypertension. They found that a prolonged venous-arterial ECMO after transplant provides excellent results in comparison with the standard management without prolonged support. They reported one- and five-year survival rates in the prolonged ECMO group of $90.2 \%$ and $87.4 \%$, respectively (12). However, beside the evident benefits of this strategy, extracorporeal venous-arterial support exposes patients to complications related to the ECMO technology itself (11). More frequent complications (infection or leg ischemia) are related to the site of cannulation. Moreover, the most important complication of venous-arterial ECMO is represented by the so-called "Harlequin Syndrome", characterized by a discrepancy in oxygenation between the upper and the lower part of the body. Harlequin syndrome and subsequent hypoxic brain damage must be promptly recognized and treated. Treatment is represented by the increase of ventilator support and or circulatory support to full flow or by the implementation of ECMO therapy with a venous-venous-arterial configuration. In our population a venous-arterial ECMO after transplant has never been required. In three cases (two primary pulmonary hypertension and one Eisenmenger syndrome patients) with a significant post-transplant left ventricular diastolic dysfunction, we used venous-venous ECMO in association with the insertion of an intra-aortic balloon pump (IABP). This strategy guarantees adequate oxygenation (maintaining protective or ultra-protective ventilation), reducing the risk of hypoxia in the upper part of the body. We acknowledge that IABP offers only a partial cardiac support, however, in our cases it was enough to allow a progressive adaptation of the left ventricle. We believe that this option can be applied in selected cases as an alternative strategy to venous-arterial ECMO after LTx, reserving the latter for the most critical patients. Early and long-term results are influenced by the need for post-transplant ECMO, although conditional survival at three months is not influenced by post-surgery extracorporeal support. Considering that in our series ECMO has been implanted as a rescue therapy for severely impaired pulmonary function and never as a preemptive strategy, our data confirm the significant impact of severe graft dysfunction on hospital and long-term results.

The retrospective, single-centre design and the relatively small sample size are the main limitations of the study.

In conclusion, although our analysis suffers of some critical points represented by the relatively small cohort of patients and the retrospective nature of our analysis, in our experience, severe graft dysfunction after LTx still has a significant impact on early and late results.

\section{Acknowledgements}

None.

\section{Footnote}

Conflicts of Interest: The authors have no conflicts of interest to declare.

\section{References}

1. Chambers DC, Yusen RD, Cherikh WS, et al. The Registry of the International Society for Heart and Lung Transplantation: Thirty-fourth Adult Lung And HeartLung Transplantation Report-2017; Focus Theme: Allograft ischemic time. J Heart Lung Transplant 2017;36:1047-59.

2. Boffini M, Ranieri VM, Rinaldi M. Lung transplantation: is it still an experimental procedure? Curr Opin Crit Care 2010;16:53-61.

3. Del Sorbo L, Boffini M, Rinaldi M, et al. Bridging to lung transplantation by extracorporeal support. Minerva Anestesiol 2012;78:243-50.

4. Boffini M, Venuta F, Rea F, et al. Urgent lung transplant programme in Italy: analysis of the first 14 months. Interact Cardiovasc Thorac Surg 2014;19:795-800; 
discussion 800 .

5. Boffini M, Ricci D, Bonato R, et al. Incidence and severity of primary graft dysfunction after lung transplantation using rejected grafts reconditioned with ex vivo lung perfusion. Eur J Cardiothorac Surg 2014;46:789-93.

6. Boffini M, Ricci D, Barbero C, et al. Ex vivo lung perfusion increases the pool of lung grafts: analysis of its potential and real impact on a lung transplant program. Transplant Proc 2013;45:2624-6.

7. Terragni PP, Fanelli V, Boffini M, et al. Ventilatory Management During Normothermic Ex Vivo Lung Perfusion: Effects on Clinical Outcomes. Transplantation 2016;100:1128-35.

8. Cypel M, Levvey B, Van Raemdonck D, et al. International Society for Heart and Lung Transplantation Donation After Circulatory Death Registry Report. J Heart Lung Transplant 2015;34:1278-82.

9. Van Raemdonck D, Hartwig MG, Hertz MI, et al. Report of the ISHLT Working Group on primary lung graft dysfunction Part IV: Prevention and treatment: A 2016 Consensus Group statement of the International Society

Cite this article as: Boffini M, Simonato E, Ricci D, Scalini F, Marro M, Pidello S, Attisani M, Solidoro P, Lausi PO, Fanelli V, Barbero C, Brazzi L, Rinaldi M. Extracorporeal membrane oxygenation after lung transplantation: risk factors and outcomes analysis. Ann Cardiothorac Surg 2019;8(1):54-61. doi: 10.21037/acs.2018.12.10 for Heart and Lung Transplantation. J Heart Lung

Transplant 2017;36:1121-36.

10. Bhabra MS, Hopkinson DN, Shaw TE, et al. Controlled reperfusion protects lung grafts during a transient early increase in permeability. Ann Thorac Surg 1998;65:187-92.

11. Tudorache I, Sommer W, Kühn C, et al. Lung transplantation for severe pulmonary hypertension--awake extracorporeal membrane oxygenation for postoperative left ventricular remodelling. Transplantation 2015;99:451-8.

12. Moser B, Jaksch P, Taghavi S, et al. Lung transplantation for idiopathic pulmonary arterial hypertension on intraoperative and postoperatively prolonged extracorporeal membrane oxygenation provides optimally controlled reperfusion and excellent outcome. Eur J Cardiothorac Surg 2018;53:178-85.

13. Hoetzenecker K, Schwarz S, Muckenhuber M, et al. Intraoperative extracorporeal membrane oxygenation and the possibility of postoperative prolongation improve survival in bilateral lung transplantation. J Thorac Cardiovasc Surg 2018;155:2193-206.e3. 